\title{
Melissa: desenvolvimento de produto em sintonia com a pesquilsa de tendências
}

Melissa: product development tuned with trends research

Bruna Machado

Mestranda, Universidade do Estado de Santa Catarina, SC brunarosamachado@gmail.com

Murilo Scóz

Doutor, Universidade do Estado de Santa Catarina,SC

muriloscoz@gmail.com 


\title{
Melissa: desenvolvimento de produto em sintonia com a pesquisa de tendências
}

Melissa: product development tuned with trends research

Bruna Machado, Murilo Scóz

\section{Resumo}

Julia Joner é designer de moda e, atualmente, atua como supervisora da equipe de design da marca de calçados Melissa. A entrevista evidencia processos produtivos da empresa, suas dinâmicas criativas e como a pesquisa de tendências é integrada ao processo de desenvolvimento de produtos.

Palavras-chave: design de produto, pesquisa de tendências, melissa

\begin{abstract}
Julia Joner is a Fashion Designer who, at the moment, works as a supervisor of the Design team of shoewear brand Melissa. The interview shows the company productive processes, their creatives dynamics and how trends research is integrated into product development.
\end{abstract}

Keywords: product design, trends research, melissa 


\section{Apresentação}

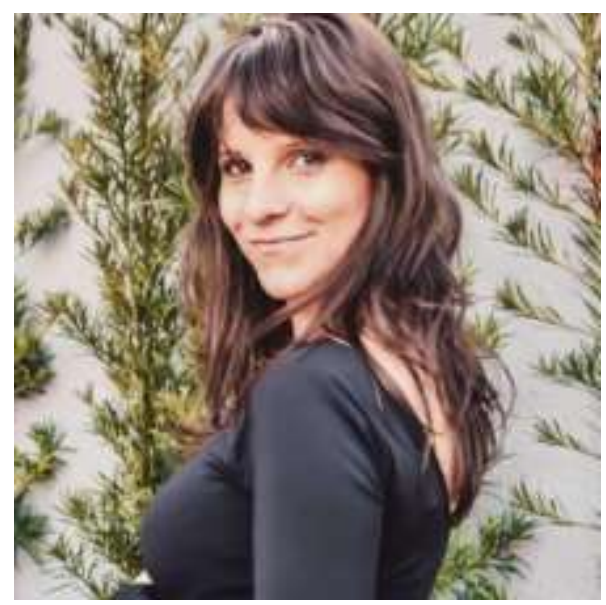

Figura 1: Julia Joner (arquivo pessoal)

Julia Joner é gaúcha, formada em Design de Moda pela Universidade de Caxias do Sul (UCS). Atualmente, ocupa o cargo de supervisora da equipe de design da Melissa. Sua trajetória profissional se iniciou em 2009, como estilista na empresa infantil 3ejá, e, em 2012, ingressou como analista de pesquisa do segmento kids na Grendene. Na empresa, passou pela área de Marketing até chegar no desenvolvimento de produto da marca Melissa. Desde 2016, ocupa o cargo de supervisão. Nesta entrevista, Joner aborda a importância do processo de pesquisa de tendências dentro da empresa e descreve como o mesmo é incorporado ao desenvolvimento de produtos da Melissa.

\section{Entrevista}

a. A Grendene conta com marcas expressivas no segmento do calçado, cada qual atendendo à um diferente mercado consumidor. Como estão organizadas as equipes criativas para desenvolver estas marcas e seus respectivos produtos?

O Diretor do Departamento de Design é o Edson Matsuo e, dentro deste GD, temos todas as linhas Melissa, Ipanema, Grendha, etc. Cada uma é segmentada e tem o seu núcleo de design, que conta com um gerente, um coordenador e um supervisor. Eu, como supervisora da equipe de design da Melissa, tenho como foco principal as pessoas e suas dinâmicas. Na equipe temos também um especialista em tendências, que está sempre captando as 
tendências nas áreas da moda, comportamento, consumo, e é a "porta" de informações para o grupo.

\section{b. Como está organizada a equipe Melissa?}

Na equipe, nos dividimos da seguinte forma: temos os designers de produto "1" e "2". Os designers "1", normalmente, são aqueles que ainda estão estudando, iniciando sua carreira, enquanto que os designers "2" possuem um pouco mais de bagagem e experiência. Temos então os designers de composição, que trabalham toda a parte de superfície e acabamento e, também, as especificações técnicas. Na área de tendências, temos um especialista em pesquisa no time, o Everson Barboza.

No total, somos dez designers para desenvolvimento e dois em composição. Estamos trazendo, para o grupo, um projetista e um responsável pelo pre-render, mas estes profissionais ainda estão em processo de incorporação.

$\mathrm{Na}$ articulação de trabalho, operamos com uma divisão de jobs: renovações de produtos de base, aqueles que são recorrentes nas coleções e são atualizados a cada temporada; a mini melissa, que é coleção infantil da marca; os projetos da coleção, nos quais temos mais informação de tendências e, também, os licenciados, aqueles projetos colaborativos que são as parcerias que a Melissa articula, no qual temos uma pessoa dedicada para desenvolver full time os licenciados internacionais, Vivienne Westwood, Jason Wu, Baja East; e outra designer dedicada às parcerias nacionais, Herchcovitch, Salinas.

\section{c. Com um número expressivo de profissionais de criação e} design na equipe, é natural a atenção sobre as dinâmicas da moda. Em que momento a pesquisa de tendências é inserida no processo de desenvolvimento de produto?

Ainda trabalhamos com duas grandes coleções no ano, primavera/verão e outono/inverno, mas que, cada vez mais, vêm se tornando coleções atemporais, com um mix de produtos bem equilibrado, visto que a marca é global e precisa atender o mercado nacional e internacional. Isso faz com que tenhamos desde bota cano alto à sandália em ambas as coleções. 
Quanto ao nosso processo de desenvolvimento, ele se inicia na imersão criativa, em que toda a equipe de design, e uma parte chave da equipe de marketing e comercial, trabalham juntas durante uma semana. $O$ objetivo da imersão é desenvolver uma coleção de doze novos produtos. Para este encontro, existe uma preparação intensa do material de tendências, que será apresentado pelo Everson Barboza, especialista em tendências da nossa equipe. O período em que acontecem as imersões é entre os meses de março a abril, para a coleção outono/inverno, e entre agosto a setembro para a coleção primavera/verão. Como preparativo para a imersão, o Everson viaja um mês antes para algum local que seja relevante, pode ser Japão, Rússia, Londres, enfim... Lá, ele coleta as informações necessárias, busca referências, tanto de comportamento quanto de produto, e, na volta, compila este material numa apresentação. Em todo este processo, ele é acompanhado por um profissional do marketing da Melissa, o Cássio Prates, e, em equipe, formam uma espécie de "antena de tendências", trabalhando sempre em conjunto. Além dessa viagem, nós temos acesso ao portal de tendências WGSN; à revistas especializadas e outras fontes de pesquisa, mas vejo que o principal norteador é o "olhar deles", que tem este caráter de trendhunter.

Também, é importante lembrar que nos preparativos para imersão, temos a consultoria da Erika Palomino, que traz uma diretriz a respeito de temas. A abordagem que ela traz é mais macro, com sugestões de temas amplos que não contemplam referências de produto, mas estão mais ligados à comportamento. Este material, igualmente, é compartilhado com a equipe, o que já permite que todos fiquem na mesma "batida", conectados com os temas que estamos vislumbrando para poder alimentar suas pesquisas individuais.

\section{d. Como se dá o processo da imersão?}

Já fizemos estes encontros em diversos lugares, porém em função da disponibilidade de material para fazer mock ups, pelas dúvidas sobre os projetos que estão acontecendo e pela velocidade como as coisas acontecem, temos feito na nossa sede, aproveitando a disponibilidade da equipe que está presente. 
Iniciamos com os especialistas em tendências apresentando o material produzido, que contempla a parte comportamental e os produtos já divididos por moods e, a partir daí, a equipe vai trabalhar os produtos em si. Neste início, já existe uma ideia de briefing com a descrição de produtos, por exemplo sapatilha fechada, chinelo, bota, etc... Assim, já se estabelece uma direção para o desenvolvimento e abrem-se alguns caminhos. Nos dividimos em grupos, que trabalham juntos, e a ideia é sair dessa semana de imersão com mock ups iniciais, ou seja, ter "manchas" de produtos já direcionados.

Ao final, os protótipos são apresentados para o grande grupo, com uma rodada de discussões, na qual cada membro das equipes expressa sua opinião, o que leva a novos insights. Então, este acaba sendo o enfoque principal dessa semana: se alimentar dos temas mais subjetivos e os materializar durante o período da imersão, o que termina por criar propostas concretas, físicas. Como encerramento da imersão, uma apresentação formal é feita para os gerentes e diretores. Isso faz com que gere um fio condutor entre a equipe de design, marketing e comercial, para que tudo aconteça alinhavado no desenrolar da coleção.

e. Quais os desafios do desenvolvimento de produto, a partir dos estudos de tendências, em uma marca como a Melissa, que se posiciona de forma vanguarda, mas que também atende a um mercado de massa?

Essa é a tensão eterna entre o design e o comercial. Nós, designers, estamos olhando tudo que é referência atual, global, a gente quer mais é fazer o disruptivo, o diferente, mas este balanço é feito junto com o departamento comercial. A gente não pode perder a característica vanguarda da Melissa, porque ela permite que a gente continue vendendo para o mercado de massa, pois mesmo que a "massa" não compre estes produtos, eles se importam com estes atributos e precisam saber que a Melissa está entregando.

Neste sentido é bem desafiador pensar no tamanho do público com que estamos conversando, reconhecer que não há mais gênero, classe, idade ou outro atributo que limite ou crie uma barreira para a Melissa. Nós, obviamente, focamos num público, de 14 a 30 anos, mas as fronteiras desta 
faixa já não são tão evidentes. E acho que é um grande momento para a moda, em termos de globalização, a questão do acesso à informação que as pessoas têm. As marcas no Brasil, hoje, conseguem entregar signos de moda que, antes, não conseguiam. Querendo ou não, Melissa também tem esse papel, no Brasil, ao colocar essa informação ao alcance do grande público, em escala e na grande mídia. No geral, a marca tem entre cem, cento e vinte projetos. E dentro desses, existem doze que são novos; quatro são oportunidades; então dos cento e vinte, quatro são os disruptivos; os demais são renovações de produtos que dão certo, já conhecidos na coleção da Melissa, como o Beach Slide, Cosmic, Ultragirl.

f. Além dos números do departamento comercial, num processo tão dinâmico e que ao mesmo tempo exige tanto das equipes de criação, como pode ser avaliado o sucesso de uma coleção?

Eu percebo o sucesso quando tenho a equipe engajada, unida, livre de qualquer desentendimento, que a gente sabe que acontece com equipes grandes. Então, esses momentos de pleno engajamento são mágicos e vejo uma grande diferença no resultado dos processos. Já tivemos momentos de imersão, que não foram tão bons quanto outros. Durante o desenvolvimento desta última coleção, a Mapping, a imersão foi fantástica; o tema estava todo alinhado; rendeu uma boa apresentação e, também, uma boa convenção e está tendo uma boa mídia. Como um dos resultados, a equipe estabelece uma relação próxima e bastante emocional com os produtos, lembrando de cada etapa com muito carinho e, isso, eu vejo como sucesso. 